\title{
PATTERNS OF IUCD USAGE IN A MEDICAL HOSPITAL IN BIHAR
}

\author{
Tripti Sinha ${ }^{1}$
}

${ }^{1}$ Assistant Professor, Department of Obstetrics and Gynaecology, Sri Krishna Medical College, Muzaffarpur, Bihar, India.

\section{ABSTRACT}

\section{BACKGROUND}

The GOI's emphasis is now diversifying from birth-limiting sterilisations to birth-spacing methods like intra-uterine contraceptive device. Research is needed to study the current usage of IUCDs, analyse reasons for its low acceptance and formulate policies and programs to increase its acceptance.

Our study aims to define the popularity of the IUCD in a population accessing health services in a Medical College in Bihar.

The study is conducted in Sri Krishna Medical College, Muzaffarpur, in Bihar which predominantly serves a rural population. It is a retrospective case note analysis.

\section{MATERIALS AND METHODS}

Relevant data over a three-year period was collected from case records and hospital registers.

\section{RESULTS}

Out of $1058 \mathrm{CuT} 380 \mathrm{~A}$ insertions, 962 (90.93\%) were postpartum insertions at caesarean sections. IUCDs were also inserted at uterine evacuation procedures and as interval contraception. There were 127 removals.

\section{CONCLUSION}

Our results emphasise the importance of counseling all women about the advantages and availability of IUCDs in government healthcare facilities when they come for delivery, pregnancy termination or miscarriage management, or request contraception as interval procedure. This would drastically reduce the unmet need for contraception of vulnerable women in the reproductive age-group.

\section{KEY WORDS}

Janani Bal Suraksha Yojna, PPFP, Postpartum Intra-Uterine Contraceptive Device, Long Acting Reversible Contraceptive, Vaginal Delivery, Caesarean Section, Pregnancy Termination, Uterine Evacuation, Expulsions, Removal.

HOW TO CITE THIS ARTICLE: Sinha T. Patterns of IUCD usage in a medical hospital in Bihar. J. Evolution Med. Dent. Sci. 2018;7(49): 5246-5249, DOI: $10.14260 /$ jemds/2018/1164

\section{BACKGROUND}

Beyond the widely publicized aims of Janani Bal Suraksha Yojna (JBSY) initiative of the National Health and Population Control Policy of India to improve antenatal care coverage of pregnant women and achieve $100 \%$ institutional delivery rate in order to directly reduce maternal morbidity and mortality, the often under-emphasized aim is to address the unmet need for contraception especially for rural women.(1)

The PPFP interventions focus on this aim by providing contraceptive counseling and service provision to those women who deliver in health care facilities. IUCD insertion in the immediate post placental delivery period till up to 48 hours postpartum while the parturient is still in the health care facility is one such contraceptive choice available to reduce the number of unwanted and unplanned pregnancies significantly.

\section{MATERIALS \& METHODS}

The present study was conducted in Sri Krishna Medical College Hospital, Muzaffarpur, which has a wide obstetric catchment area for patients who reach it from within its district boundaries as well as from adjacent districts. Women

'Financial or Other Competing Interest': None.

Submission 18-10-2018, Peer Review 13-11-2018,

Acceptance 20-11-2018, Published 03-12-2018.

Corresponding Author:

Dr. Tripti Sinha,

\#705 North, Udaigiri Bhawan,

Budh Marg Opposite Old Patna Museum,

P. S. Kotwali, Patna-800001,

Bihar, India.

E-mail: triptisinha0304@gmail.com

DOI: $10.14260 /$ jemds $/ 2018 / 1164$

\section{(c) $($ ) $\$$}

come preponderantly from rural areas often with poor access to suitable delivery facilities and contraceptive provision services.

This study is a retrospective case note analysis for a 3-year period from February 2015 till January 2018. The profile of women in whom IUCD was inserted and timing of its insertion were noted. The analysis of the data provides guidelines to improve the uptake of this long acting reversible contraceptive (LARC) method which has been very successful in other similar low-resource settings.

Doctors working in the Obstetrics and Gynaecology were trained in IUCD insertions as interval procedures or after procedures to evacuate the pregnant uterus as part of their medical curriculum. PPIUCD insertion training was imparted on-site to doctors and staff nurses by JHpiego master trainers. CuT $380 \mathrm{~A}$ was provided in the delivery suite, gynaecology and obstetrics operation theatres. In the busy antenatal and gynaecology clinic there was scanty opportunity to counsel women about the contraceptive options available to them in the hospital. They were offered the choice of IUCD while they were in early labour or immediately after vaginal delivery, before being taken for caesarean section or uterine evacuation procedures. This was due to non -availability of family planning counsellors in the obstetrics and gynaecology unit of the hospital.

\section{RESULTS}

There were 1058 CuT 380A IUCD insertions in the study period. There was a wide variation in the number of insertions every month. The overall trend was worrying with a sharp 
decline in insertions- 630 between February 2015 - January 2016, 280 between February 2016- January 2017 and only 131 between February 2017-January 2018. Even more worrying was the observation of 28,36 and $63 \mathrm{CuT}$ removals in the corresponding consecutive time periods. However, it was not clear from the HMIS data of the hospital where and when the IUCDs were inserted in those women who requested removals. (Table 1).

\begin{tabular}{|c|c|c|}
\hline Year & Insertions & Removals \\
\hline Feb. 2015-Jan. 2016 & 630 & 28 \\
\hline Feb. 2016-Jan. 2017 & 280 & 36 \\
\hline Feb. 2017-Jan. 2018 & 131 & 63 \\
\hline \multicolumn{2}{|c|}{ Table 1. Number of Insertions and Removals of IUCD in } \\
Consecutive Years (Feb. 2015-Jan. 2018)
\end{tabular}

Table 2 shows the age distribution, parity and religion of the women who accepted IUCD as a contraceptive choice. 37 (3.49\%) women were in the teenage group, 969 (91.59\%) were in age group 20-30 years, 46 (4.35\%) were between 3140 years and $6(0.57 \%)$ were above 40 years. Their parity ranged from primipara to grand multipara, majority being para 2 and para $3.475(44.9 \%)$ users were primipara, 564 (53.31\%) were para 2 or para 3 and $19(1.79 \%)$ women were para 4 or over. 926 (87.52\%) users were Hindus and 132 (12.48 \%) were Muslims.

\begin{tabular}{|c|c|c|c|}
\hline \multicolumn{2}{|c|}{ Patient Characteristic } & Number (n) & Percentage (\%) \\
\hline \multirow{4}{*}{ Age(yrs.) } & Teenage & 37 & 3.49 \\
\cline { 2 - 4 } & $21-30$ & 969 & 91.59 \\
\cline { 2 - 4 } & $31-40$ & 46 & 4.35 \\
\cline { 2 - 4 } & $>40$ & 6 & .57 \\
\hline \multirow{4}{*}{ Parity } & Primipara & 475 & 44.9 \\
\cline { 2 - 4 } & Para 2-para 3 & 564 & 53.31 \\
\cline { 2 - 4 } & Para 4 \& $>$ & 19 & 1.79 \\
\hline \multirow{2}{*}{ Religion } & Hindu & 926 & 87.52 \\
\cline { 2 - 4 } & Muslim & 132 & 12.48 \\
\hline \multicolumn{2}{|r}{ Table 2. Demographic Profile of IUCD Acceptors } \\
\hline
\end{tabular}

Table 3 shows the timing of insertion of the IUCD. $962(90.93 \%)$ were inserted at Caesarean section as part of PPFP provision, 61 (5.77\%) were after D\&E, 15 (1.42\%) were after a MVA or other surgical pregnancy termination procedure and $20(1.80 \%)$ were interval insertions. All PPIUCD insertions were done by doctors at the time of caesarean delivery. There were no PPIUCD insertions in the delivery room immediately after placental delivery or in the postnatal ward within 48 hours before the woman was discharged. All IUCDS inserted were CuT 380 A with efficacy for 10 years.

\begin{tabular}{|c|c|c|}
\hline Procedure & Number(n) & Percentage (\%) \\
\hline Caesarean Section & 962 & 90.93 \\
\hline D \& E & 61 & 5.77 \\
\hline $\begin{array}{c}\text { Surgical MTP } \\
\text { Procedure }\end{array}$ & 15 & 1.42 \\
\hline Interval Insertion & 20 & 1.89 \\
\hline \multicolumn{2}{|c|}{ Table 3. Timing of Insertion of IUCD } \\
\hline
\end{tabular}

Table 4 shows the indications of Caesarean sections in which CuT 380A was inserted.

\begin{tabular}{|c|c|c|c|}
\hline $\begin{array}{c}\text { Sl. } \\
\text { No. }\end{array}$ & Indication & $\begin{array}{c}\text { Number of } \\
\text { Cases (n) }\end{array}$ & $\begin{array}{c}\text { Percentage of } \\
\text { Cases (\%) }\end{array}$ \\
\hline 1 & $\begin{array}{c}\text { Previous Caesarean } \\
\text { Section }\end{array}$ & 288 & 29.93 \\
\hline 2 & Obstructed Labour & 206 & 21.41 \\
\hline 3 & $\begin{array}{c}\text { Premature Membrane of } \\
\text { Rupture }\end{array}$ & 41 & 4.26 \\
\hline 4 & Post-Date Pregnancy & 26 & 2.7 \\
\hline 5 & $\begin{array}{c}\text { Antepartum } \\
\text { Haemorrhage }\end{array}$ & 33 & 3.43 \\
\hline 6 & Mal-Presentation & 126 & 13.1 \\
\hline 7 & Non-Progress of Labour & 157 & 16.32 \\
\hline 8 & Multiple Pregnancy & 5 & 0.52 \\
\hline 9 & Bad Obstetrical History & 6 & 0.62 \\
\hline 10 & Reduced Liquor & 7 & 0.73 \\
\hline 11 & Foetal Distress & 18 & 1.87 \\
\hline 12 & Cord Prolapse & 9 & 0.94 \\
\hline 13 & PIH/ Eclampsia & 27 & 2.81 \\
\hline 14 & Undocumented & 35 & 3.64 \\
\hline 15 & Less Foetal Movement & 3 & 0.31 \\
\hline
\end{tabular}

Table 4. Indications for Caesarean Section during which PPIUCD was Inserted

Analysing the indications of caesarean section at which IUCD were inserted raised some concerns. A large number of insertions were done in cases of obstructed labour, PROM, non-progress of labour in which there was no mention of how long the membranes had been ruptured and the likelihood of intra-uterine infection was high. Insertions were also done in indications like antepartum haemorrhage in which likelihood of postpartum haemorrhage is high. Both suspected or proven intra-uterine infections and haemorrhage during or after delivery or caesarean section are contra-indications to PPIUCD insertion. It is important to note down clearly in the case notes the membrane status at each pelvic examination so that PPIUCD can be inserted as per norms of less than 18 hours of membrane rupture and with no signs of intra-uterine infection

There were 8 women who tested positive for hepatitis B and 1 for HIV.

The most commonly encountered problem associated with the use of PPIUCD at the time of postnatal visits was prolonged vaginal bleeding in the puerperium and thereafter. Nonvisibility of thread at the external os was another worrying problem and very often necessitated removal of the CuT380A under general anaesthesia in the operation theatre. However, due to paucity of complete documentation it was not possible to ascertain whether the IUCD removals done in the O.T. were in cases which had interval insertions, after vaginal delivery or at caesarean delivery, at which health facility the insertion was done and whether any difficulty was experienced at the time of removal. For the same reason the frequency of these problems could not be determined in our study population as well as the reasons for the removals.

\section{DISCUSSION}

IUCD is a well-considered choice for women in whom permanent method of contraception is either not suitable or who want to retain their reproductive potential while avoiding an unplanned unwanted pregnancy. Hence, it is an appropriate choice for primipara who can delay her next pregnancy till the ideal pregnancy spacing interval of minimum two years.

IUCDs are gaining favour in the National Population Policy in India as a method with great potential as a long- acting reversible contraceptive (LARC). CuT $380 \mathrm{~A}$ is freely available 
in government facilities in all states including Bihar. The challenge to health -care providers catering to the health needs of the women in the reproductive age group is to generate demand for this form of LARC in the vulnerable agegroup and motivate them to accept this highly effective and safe method for birth spacing and even birth-limiting purpose. Its major advantage is that the reproductive potential of the acceptor remains unimpaired which increases its appeal in certain sections of the community both in rural and urban areas. It is encouraging to note that IUCDs especially PPIUCD was being accepted by the minority community although the percentage of acceptors is less compared to other sections of the population. This is similar to the findings of Gadre and Ahirwar.(2) Well- tailored IEC material can get more families across all communities to opt in for this non-permanent longlasting safe effective contraceptive choice.

Similarly, women having their second or third child are hesitant about accepting permanent methods of family planning but have also decided that they would like to limit their family size. In such situations IUCD is an attractive and sensible option. It instils confidence in the user that she is in control of her future reproductive needs and wishes. Our study highlights that most of the IUCD users are para 2 or 3 . A significant number of higher parity women who did not accept sterilization to limit family size agreed for IUCD insertion which could effectively take them beyond their reproductive years. This has observed in other studies also Anguzu et al.(3)

There are several opportunities when women vulnerable to unplanned unwanted pregnancies interact with health care providers and can be counseled to accept this method of family planning. At the time of initial counseling and insertion it is of paramount importance to stress the importance of follow-up visits so any insertion- related problem can be dealt with thus improving continuation rates and minimizing removals. Women who approach health care systems for delivery, miscarriage or pregnancy termination are particularly likely to accept this form of contraception at the same visit rather than escape the contraceptive net.

A very worrying observation in our study is that IUCDs were being inserted chiefly during caesarean sections and other opportunities for its insertion were missed - interval insertions, after surgical terminations of pregnancies, at evacuation of non-viable pregnancies or immediately following placental delivery at vaginal births or within 48 hours. Such insertions can be increased by enlisting the help of a family planning counsellor who actively interacts with women in such situations. It is also of concern that despite being trained in PPIUCD insertions the nursing staff was not inserting them after vaginal delivery. This highlights the importance that they need support to increase their confidence in this procedure. Since 2013 GOI has recognized the need for task sharing in PPIUCD insertion. Studies have shown that with proper training nursing staff can safely do insertions with good client satisfaction rates at follow up visits. $(4,5)$

One significant limitation of our study is that our patients mostly did not come for follow-up at the scheduled postnatal visit or/and thereafter; neither was there telephonic followup. Therefore, not much can be inferred from this study regarding expulsion rates, menstruation - related problems and overall patient satisfaction with postpartum IUCD insertion. This shortcoming highlights the need to improve the maintenance of records and registers all health-care facilities.

Other studies report some follow-up data following PPIUCD insertions after vaginal or caesarean delivery. Hooda et al report a follow up visit rate of $28.8 \%$ after PPIUCD insertions. 55\% were after caesarean section. There were no case of uterine perforation or unplanned pregnancies but there were women coming back with complaints of unusual vaginal discharge, abnormal uterine bleeding or expulsions, requests for removals for personal or medical reasons; or there was non-visualisation of threads at pelvic examination.(6)

In another study by Shukla et al in which CuT 200B were inserted in 1317 women $78 \%$ women came for follow-up at 6 weeks but only $11.3 \%$ at 6 months (7). In the study by Janwadkar and Shekhawat, 83\% PPIUCD acceptors had followup contact by 6 weeks either by hospital visit (41\%) or by telephonic contact (59\%). The couple satisfaction rate was as high as $73-78 \%$; expulsions were $13.6 \%$, abnormal uterine bleeding $4.1 \%$, infection, demand for removal for whatever reason $24.7 \%$ and willingness to continue usage of IUCD $75.3 \%{ }^{(8)}$ Celen et al observed that the incidence of perforation and infection was not increased by IUCD insertion during postpartum period compared to other timings of insertion(9).

Early follow-up examination following IUCD insertion is important to identify spontaneous expulsion and provide alternative contraception or IUCD re-insertion. Expulsion rates vary according to clinician skill. Additional training and special insertion kits should be provided to health centres where deliveries are conducted.(10,11)

\section{CONCLUSION}

Increasing the acceptance of the intra-uterine devices is a very important responsibility of all stake holders involved in delivering contraceptive services to women attending healthcare facilities. Demand generation can be augmented by exploring all opportunities within the obstetric and gynaecological setup so that women are not deprived of the advantages of this long acting reversible contraception which effectively addresses the expectations and concerns of most women in the reproductive age-group.

\section{REFERENCES}

[1] National Population Policy 2000: Department of Family Welfare, Ministry of Health \& Family Welfare, GOI, Nirman Bhawan, New Delhi.

[2] Gadre SS, Ahirwar R. Level of acceptance of IUCD insertion in Indian women - a cross-sectional mixed research from central India. Int J Reprod Contracep Obstet Gynecol 2015;4(4):1079-85.

[3] Anguzu R, Sempeera H, Sekandi JN. High parity predicts use of long-acting reversible contraceptives in the extended postpartum period among women in rural Uganda. Contraception and Reproductive Medicine 2018;3:6.

[4] Yadav V, Balasubramaniam S, Das S, et al. Comparison of outcomes at 6 weeks following postpartum intrauterine contraceptive device insertions by doctors and nurses in India: a case - control study. Contraception 2016;93(4):347-55. 
[5] Pfitzer A, Mackenzie D, Blanchard H, et al. A facilitybirth can be the time to start family planning: postpartum intrauterine device experiences from six countries. Int J Gynecol Obstet 2015;130(Suppl 2):55461.

[6] Hooda R, Mann S, Nanda S, et al. Immediate postpartum intrauterine contraceptive device insertions in Cesarean and vaginal delivery: a comparative study of follow-up outcomes. Article ID 7695847, Int J Reprod Med 2016;2016: p. 5.

[7] Shukla M, Qureshi S, Chandrawati. Post-placenta intrauterine contraceptive device insertion - a five year experience at a tertiary care centre in North India. Int J Med Res 2012;136(3):432-5.
[8] Janwadkar A, Shekhawat GS. Acceptance, perception, experience and satisfaction of the couple with postpartum intrauterine contraceptive devices (PPIUCD) insertions. Asian Pac J Health Sci 2016;3(4):55-64.

[9] Celen S, Moroy P, Sucek A, et al. Clinical outcomes of early post-placental insertion of intra-uterine contraceptive devices. Contraception 2004;69(4):27982.

[10] Thiery M, Van Kets H, Van der Pas H. Immediate postplacental IUD insertion: the expulsion problems. Contraception 1985;31(4):331-49.

[11] Muthal-Rathore A. Geneva: World Health Organisation, Immediate postpartum insertion for intra-uterine devices. RHL commentary, The WHO Reproductive Health Library, 2010. 